\title{
TENSILE CREEP OF A STRUCTURAL EPOXY ADHESIVE: EXPERIMENTAL AND ANALYTICAL CHARACTERIZATION
}

\author{
Inês COSTA ${ }^{1}$ \\ $\mathrm{PhD}$ - Engineer \\ ISISE - University of Minho \\ Department of Civil Engineering, Campus de Azurém, 4800-058 Guimarães, Portugal \\ inescosta@civitest.com

\section{Joaquim BARROS} \\ Full Professor \\ ISISE - University of Minho \\ Department of Civil Engineering, Campus de Azurém, 4800-058 Guimarães, Portugal \\ barros@civil.uminho.pt
}

\section{Abstract}

Epoxy adhesives are nowadays being extensively used in Civil Engineering applications, mostly in the scope of the rehabilitation of reinforced concrete (RC) structures. In this context, epoxy adhesives are used to provide adequate stress transference from fibre reinforced polymers (FRP) to the surrounding concrete substrate. Most recently, the possibility of using prestressed FRPs bonded with these epoxy adhesives is also being explored in order to maximize the potentialities of this strengthening approach. In this context, the understanding of the long term behaviour of the involved materials becomes essential. Even when non-prestressed FRPs are used a certain amount of stress is permanently applied on the adhesive interface during the serviceability conditions of the strengthened structure, and the creep of the adhesive may cause a continuous variation in the deformational response of the element. In this context, this paper presents a study aiming to experimentally characterize the tensile creep behaviour of an epoxy-based adhesive currently used in the strengthening of concrete structures with carbon FRP (CFRP) systems. To analytically describe the tensile creep behaviour, the modified Burgers model was fitted to the experimental creep curves, and the obtained results revealed that this model is capable of predicting with very good accuracy the long term behaviour of this material up to a sustained stress level of $60 \%$ of the adhesive's tensile strength.

Keywords: Epoxides; concrete; experimental characterization; rheology; mechanical properties.

${ }^{1}$ Corresponding Author. Tel: +351 252315199.

E-mail address: inescosta@civitest.com (Inês G. Costa). 


\section{$34 \quad 1$ Introduction}

35 One of the most common uses of fibre reinforced polymers (FRP) in Civil Engineering applications is in the scope of rehabilitation and strengthening of reinforced concrete (RC) structures. For that purpose, the FRPs, in the form of sheets, laminates or bars, are bonded to the existing structures by means of an adhesive. The research group at Minho University has already applied these FRPs externally (externally bonded reinforcement - EBR), near surface mounted (NSM) [1] or even embedded through-section (ETS) [2]. The installation of NSMFRPs is able of increasing the load carrying capacity of a structural element with minor aesthetical impact and negligible structural weight increase, among a number of other advantages as referred by Lorenzis \& Teng [3]. Most recently, in order to take advantage of the high tensile strength of the FRP, the possibility of applying FRPs with a certain prestress is being further explored for increasing the load carrying capacity of a strengthened element at serviceability limit state conditions [4-5].

Generally, the effectiveness of these strengthening systems is, in a first phase, evaluated by means of monotonic tests, meaning that a model of the structural system is constructed and loaded up to failure. However, this type of characterization only provides the maximum expectable strength and not the real deformational behaviour of the strengthening system during the working life of the structure.

Mainly motivated by the interest of using prestressed NSM-FRPs (Figure 1), the knowledge of the long term deformability of the intervening materials becomes essential. The creep of structural adhesives is already recognized to be a material property of major importance to guarantee adequate stress transfer between the FRP and surrounding material over time. In fact, Quantrill \& Hollaway, Nordin \& Täljsten and Wang et al. have already exposed that this property plays an important role on the long term efficacy of the strengthening system [6-8]. However, the investigation in this area is scarce, despite the potentially negative effects the creep behaviour of adhesives can have in terms of the strengthening effectiveness of a FRPbased system.

Creep, usually defined as the increase of deformation over time under sustained stress, is recognized to be a relevant phenomenon when dealing with adhesives, and ISO and ASTM already define the methods to assess this property [9-10]. Additionally, the analysed specialized bibliography on this topic revealed that the mechanical performance of adhesives changes in fact with time, mainly due to the level of applied stress, but also due to environmental 
conditions such as temperature and humidity, as referred by ASTM, Dean and Feng et al. [10$12]$.

The creep behaviour of adhesives is frequently modelled using rheological models and is usually illustrated by means of Hookean springs and Newtonian dashpots that replicate, respectively, the elastic and viscous components of the material's behaviour (Brinson \& Brinson, [13]). Burgers model, depicted in Figure 2, is the most common and generalist creep model. This model is able of describing the time-strain variation of most of the existing epoxy-based adhesives, and will therefore be taken as reference to describe the behaviour of the adhesive adopted in the present research program. This model is simulated by the following equation:

$$
\varepsilon_{\text {creep }}(t)=\frac{\sigma}{E_{M}}+\frac{\sigma}{\eta_{M}} t+\frac{\sigma}{E_{K}}\left(1-\exp \left(-\frac{E_{K}}{\eta_{K}} t\right)\right)
$$

where $\varepsilon_{\text {creep }}(t)$ is the strain evaluated at a certain time instant $t, \sigma$ is the applied stress, $E_{M}$ and $\eta_{M}$ are Maxwell's elastic modulus and coefficient of dynamic velocity, $E_{K}$ and $\eta_{K}$ are Kelvin's elastic modulus and coefficient of dynamic velocity.

Feng et al. [12] suggested that the tensile creep strain, $\varepsilon_{\text {creep }}(t, T)$ can be estimated by the exponential function shown in Eq. 2, which was re-written to improve the resemblance with the rheological model that will be afterwards reported in the present document.

$$
\left.\varepsilon(t, T)=\frac{\sigma_{0}}{E_{0}}+\sigma_{0} \frac{(1}{E_{e}}-\frac{1}{E_{0}}\right)\left(\mid\left(-e^{-\left(t / t^{*}\right)^{-n}}\right)\right.
$$

where $\sigma_{0}$ is the applied stress level, $E_{0}$ the initial Young modulus, $E_{e}$ is the equilibrium modulus given in Eq. $3, t^{*}$ is the retardation time and $n$ is a coupling parameter related to moisture absorption.

$$
E_{e}=2 G_{r}(1+v)
$$

where $G_{r}$ is the rubbery plateau shear modulus and $v$ is the Poisson's ratio ( $v=0.5$ since the material is in the rubbery state).

The unique feature of this model is related to the $n$ parameter, whose value is basically related to the activation energy of the molecular motion. If a specimen is saturated, the presence of moisture enhances the molecular mobility and, therefore, decreases the amount of activation energy required, resulting in lower values of $n$. As reference, it can be mentioned that Feng et al. [12] obtained in their tests an initial Young modulus, $E_{0}$, of $2.5 \mathrm{GPa}$, retardation 
times, $t^{*}$, ranging between 54 and 16204 days and values of $n$ ranging from 0.51 to 0.73 for varying degrees of relative humidity.

In another paper, Majda \& Skrodzewicz [14] proposed a model purely based on Burgers Model (Eqs. 4 and 5). The singularity recognized in this paper is the suggestion that the coefficients of dynamic viscosity, $\eta_{0}$ and $\eta_{1}$, are primarily dependent on the applied stress (see Eqs. 6 and 7). Additionally, the elastic modulus of the relaxation response, herein designated as $E_{1}$, was also defined as a function of the applied stress (Eq. 8).

$$
\begin{gathered}
\varepsilon(t, T)=\frac{\sigma_{0}}{E_{0}}+\frac{\sigma_{0}}{\eta_{0}} t+\frac{\sigma_{0}}{E_{1}}\left(1-e^{-t / t^{*}}\right) \\
t^{*}=\frac{\eta_{1}}{E_{1}} \\
\eta_{0}\left(\sigma_{0}\right)=e^{a_{1}-a_{2} \sigma_{0}} \\
\eta_{1}\left(\sigma_{0}\right)=e^{a_{3}-a_{4} \sigma_{0}} \\
E_{1}\left(\sigma_{0}\right)=a_{5} \sigma_{0}^{2}-a_{6} \sigma_{0}+a_{7}
\end{gathered}
$$

As an indication, Majda \& Skrodzewicz [14] obtained an initial elastic modulus, $E_{0}$, of $2.323 \mathrm{GPa}$ and retardation times, $t^{*}$, of 3 to 24 minutes. Note that this last value is exceptionally lower when compared to the one obtained by Feng et al. [12].

Taking into account the information previously exposed, and in order to address the lack of research in this topic, an experimental program was carried out aiming the assessment of the tensile creep behaviour of an epoxy-based structural adhesive, traded under the commercial name "S\&P Resin 220 epoxy adhesive", used in a commercial NSM-CFRP (carbon FRP) system. According to the material safety sheet, the epoxy resin solution is composed of bisphenol A and neopentyl glycol diglycidyl ether while the hardener contains poly(oxypropylene)diamine, triethylentetramine, piperazine and aminoethylpiperazine. For that purpose, nine dumbbell-shaped samples of adhesive were tested under three different load levels. Later, a modified Burgers equation was used to model the creep strain curves obtained, as well as the corresponding creep modulus curves.

\section{Material Characterization}

In the first phase of the experimental program the instantaneous properties of the epoxy adhesive to be tested under tensile creep were evaluated. For this purpose dumbbell-shaped specimens of adhesive were prepared observing ISO 527-2 recommendations [15]. According to this standard, the effective cross section under tensile stress should be $10 \times 4 \mathrm{~mm}^{2}$. Note that these dimensions are representative of the thickness of the adhesive layer used in the NSMCFRP strengthening technique for bonding the CFRP reinforcement to the surrounding 
concrete. In the prestressed NSM-CFRP technique developed in the research project that the present work is part of it, a thickness of about $3 \mathrm{~mm}$ was adopted. To maintain the constituents of the adhesive at $20^{\circ} \mathrm{C}$ and $60 \%$ of relative humidity while manufacturing the specimens, the containers of the constituents were transported to a climatic chamber 24 hours prior the moulding process of the specimens. The epoxy adhesive analysed is a bi-component material that, according to the supplier, should be mixed in a proportion of 1:4 (in weight). After weighting both components in the recommended ratio, the mixture was performed manually inside a bowl and using a spatula, as it would be in a real case application, and at room temperature. After obtaining a uniform colour, the mixture was poured into a silicon mould, and no efforts were made to remove air bubbles, in order to produce a final product that is in every way similar to the one obtained in an actual application. After moulding, all the specimens to be tested were again transported to the climatic chamber until the curing time was over. When the specimens were removed from the mould, the edges were gently scraped in order to remove occasional sharp edges. For the measurement of the strain during the test, a control length of $50 \mathrm{~mm}$ was adopted, as recommended by ISO 527-2, and the tensile test was performed under displacement control at a rate of $2 \mathrm{~mm} / \mathrm{min}$. Although the recommended curing time for this particular adhesive is 7 days, it was observed that after 2 days, in terms of tensile strength, $f_{a}$, and elastic modulus, $E_{a}$, the instantaneous properties were already stabilized (see Figure 3 and Table 1). Moreover, the data sheet of this adhesive reports that three days after application, it exhibits adequate bond strength to concrete. For that reason, the curing time adopted for the creep specimens was reduced from 7 days to 3 days.

\section{Tensile Creep}

The assessment of the tensile creep properties of the adhesive was performed in a mechanical creep table, schematically represented in Figure 4. Three series of specimens were prepared, and each one was made from a batch of adhesive mixed exactly 3 days prior to creep load application, always using the same container of material. All specimens were produced and stored following the same protocol detailed in section 2 and the creep tests were performed in a climatic chamber programed to maintain a constant temperature of $20^{\circ} \mathrm{C}$ and $60 \%$ of relative humidity. Each batch of adhesive produced 14 specimens: 5 for material testing at time of loading ( $72 \mathrm{~h}$ of age, herein labelled as $t=0 \mathrm{~h}$ ), 5 for material testing at the end of the creep test ( $1072 \mathrm{~h}$ of age, herein labelled as $t=1000 \mathrm{~h}$ ) and 4 for creep testing ( 3 for tensile creep test and 1 for control purposes).

Each creep specimen was instrumented with two strain-gauges type BFLA-2-3-3L from TML, with a $2 \mathrm{~mm}$ measuring length installed precisely at the geometric centre of each face (see 
Figure 5a). The reference specimen was also instrumented, but in this case with only one strain gauge to measure any possible environmental effects on the material, on the strain gauges wires, as well as other unexpected fluctuations in the readings. Although it is acknowledged that the applied strain gauge has a rather small size, due to the small grain size of the particles that compose the adhesive, the monitored section is believed to be sufficiently representative of the tensile strain field installed in the adhesive. In each series, three different load levels were applied, corresponding to approximately $20 \%, 40 \%$ and $60 \%$ of the adhesive's tensile strength indicated in Table 1 (see Figure 5b). The evolution of strain under sustained stress was recorded for 1000 hours, as recommended by ISO and ASTM [9-10].

Table 2 summarizes the average instantaneous properties determined on the specimens of the three series, and the corresponding stress-strain curves are depicted in Figure 6. In most cases, the obtained properties were relatively close to the ones presented in Table 1 . However, in Series III, the specimens exhibited an abnormally low tensile strength both at $t=0 \mathrm{~h}$ and $t$ $=1000 \mathrm{~h}$. This fact may be due either to a deficient mixture of the components, although no significant increase in porosity was observed in the failure surface between series of specimens, or eventually to the approaching of the expiration date of the material. In reality, the creep parameters presented later, in section 3.2, suggest that during the execution of this experimental program, some type of aging process might have occurred and additional tests will be carried out in due time to investigate the causes of this material degradation. Note that according to Figure 7, Series III specimens tested at $1000 \mathrm{~h}$, exhibit less voids than the specimens tested at $0 \mathrm{~h}$, even though both exhibit similar tensile strength and elastic modulus according to Table 2.

Regarding the tensile creep tests, load was applied in the specimens in approximately 3 to 5 seconds using steel plates. The effective load, $W$, applied in the creep specimens is given in Table 3 , as well as the effective applied stress, $\sigma$, that was calculated by applying the following equation:

$$
\sigma=\frac{W \cdot g \cdot \varphi}{A}
$$

where $W$ is the mass at the loaded end of the lever, $g$ is the gravitational acceleration, $\varphi(=3)$ is the amplification factor of the creep table and $A$ is the cross sectional area of the tested specimen.

In order to standardize the load application process, three load levels were defined for all three series of specimens, taking into account the geometry of the specimens and the creep table configuration. This resulted in the definition of the following mass levels: $6 \mathrm{~kg}, 11 \mathrm{~kg}$ and 17 $\mathrm{kg}$, herein labelled as A, B and C, respectively. As in series III the control tensile tests revealed 
a lower tensile strength, the effective percentage of applied stress was different from the predefined level.

\subsection{Experimental Results}

After monitoring the specimens for the required period of time, the creep strain curves were constructed. It is worth noting that the reference creep specimens did not exhibit significant strain variation over time and, therefore, the data obtained from the loaded specimens was directly used [3]. The envelope of the time versus strains recorded in the monitored faces is plotted in Figure 8, as well as the corresponding average strain, showing that in terms of shape of the creep strain curve all specimens exhibited similar time dependent variation. The largest difference between opposing strain gauges was observed in Series I, where the difference of strains was larger than $1 \%$ in Specimen C. In the remaining specimens, the difference of strains over time between opposing strain gauges was fairly similar in all cases. It is believed that this dispersion of strains is related to the heterogeneity of the adhesive mixture, caused by the manual mixing process and the subjectivity of the "uniform colour" criterion, as well as to the small size of the strain gauge reference length $(2 \mathrm{~mm})$, which may cause the reading of strains in zones with relatively different properties. It is also noteworthy that, after $1000 \mathrm{~h}$ of loading, the adhesive specimens loaded with $12 \mathrm{MPa}$ exhibited an average strain of $4.61 \%$, 5.07\% and $6.15 \%$ in Series I, II and III, respectively. However, according to the preliminary tensile tests, the ultimate strain of these samples was only about $3 \%$ (Table 1). It is also important to notice that specimen S3_C, depicted in Figure 5c, fractured at about 27 hours after load application, in the vicinity of the top anchorage, possibly due to an accidental shock against the creep table.

\subsection{Analytical Model}

216 As already suggested in section 1, the tensile creep behaviour of epoxy adhesives is usually well 217 defined using Burgers equation (Eq. 1). Observing Figure 8, it is evident that the behaviour of 218 the tested adhesive is in fact similar to the one initially proposed (see Figure 2). Therefore, considering the average strain curves obtained for each specimen, the parameters defining Eq. 1 were determined for each of the curves, as follows:

- The initial strain, $\varepsilon_{\text {creep }}(t=0)=\varepsilon_{M}$ is inversely proportional to Maxwell's elastic modulus, $E_{M}$. In this case, $E_{M}$ is given by Eq. 10 ;

- Maxwell's coefficient of dynamic viscosity is inversely proportional to the slope of the steady-state branch, $\varepsilon_{M}^{\prime}$, as given in Eq. 11;

- Kelvin's elastic modulus, $E_{K}$, is proportional to the $\varepsilon$-intercept value, $\varepsilon_{e q}$, of the steadystate branch, as defined in Eq. 12; 
- Kelvin's coefficient of dynamic viscosity, $\eta_{K}$, is related to the retardation time $t^{*}$, which corresponds to the time instant at which $63 \%$ of the Kelvin's steady-state strain is attained. This value can be calculated by first isolating Kelvin's terms in Burgers equation, as defined in Eq. 13. Considering the obtained curve, the time necessary to achieve $0.63 \varepsilon_{K}$, where $\varepsilon_{K}$ is given by $\sigma / E_{K}$, can be determined and the coefficient of dynamic viscosity, $\eta_{K}$, can be determined using Eq. 14 .

It is worth noting that the steady-state branch was in this case defined as the last third of the creep monitoring interval, i.e., from $t=666.667 \mathrm{~h}$ to $t=1000 \mathrm{~h}$.

Table 4 summarizes the parameters determined for each of the specimens, while in Figure 9 the relationship between numerical and experimental strains is presented. Although in the initial and final instants the correlation between values is satisfactory, in a great portion of the monitored interval the strains are not so well predicted. For this reason, a modified expression based on Burgers model, proposed by Feng et al. [12], was adopted in order to improve the prediction of the experimental strains. The modified equation consists of introducing a new parameter in the original form of Burgers model, $n$, resulting:

$$
\left.\varepsilon_{\text {creep }}(t)=\frac{\sigma}{E_{M}}+\frac{\sigma}{\eta_{M}} t+\frac{\sigma}{E_{K}}\left(1-\exp \left(\left(-\frac{E_{K}}{\eta_{K}} t\right)^{1-n}\right)\right)\right)
$$

Contrariwise to the previous parameters, the determination of $n$ cannot be performed based on the features of the creep strain curve. Therefore, the parameter $n$ was determined by forcing the slope between experimental and numerical values to be unitary, using the Generalized Reduced Gradient (GRG2) nonlinear optimization, available in Microsoft Excel (2010). The values obtained by this process are fairly constant, as demonstrated in Table 5, and the obtained results reveal that this model is much more accurate, as depicted in Figure 10.

Up to this point, the obtained parameters represent the best value to predict the behaviour of a single adhesive specimen. However, to validate the applicability of the model, it is necessary to 
256 determine at least one set of parameters $\left(E_{M}, \eta_{M}, E_{K}, \eta_{K}\right.$ and $\left.n\right)$ per series. Therefore, in 257 Figure 11, the parameters that are assumed to better describe the mixture of each series are 258 presented.

259 The value of $E_{M}$, depicted in $11 \mathrm{a}$, was computed as the slope of a linear regression of $\sigma$ 260 versus $\varepsilon_{M}$, as defined by the formulation of the model, Eq. 10. Similarly, in Figures 11b 261 and 11c, $\eta_{M}$ and $E_{K}$ are defined as the slope of $\sigma$ versus $\varepsilon_{M}^{\prime}$ and $\sigma$ versus $\varepsilon_{K}$, respectively, 262 Eqs. 11 and 12. Regarding the values of $\eta_{K}$ and $n$, it is not possible to define the same type of 263 relationships. For that reason, Figures $11 \mathrm{~d}$ and $11 \mathrm{e}$ depict the values of $t^{*}$ and $n$ versus the 264 applied stress level.

265 Of all the linear regressions executed, the one defining $E_{M}$ is definitely the one leading to 266 better results. $E_{M}$ is found to exhibit, within each series of specimens, an almost unitary 267 coefficient of determination, $r^{2}$, as well as an extremely low coefficient of variation, $C O V$, 268 when all series are taken into account (see Table 6). Moreover, it is worth mentioning that in all 269 cases, $E_{M}$ is larger than $E_{a}$ (see Tables 1 and 2), most likely due to the load application speed, 270 which was performed in about 3 to 5 seconds, while in the standard tensile tests it would take 271 roughly 12 to 36 seconds to achieve the same stress levels. On the other hand, the value of $\eta_{M}$, 272 which also exhibits very good $r^{2}$ values within individual series, is not able to produce 273 particularly low $C O V$ values when considering all the series ( $C O V=25 \%$, see Table 6). The 274 same is observed in the determination of $E_{K}$, which in general leads to relatively high $r^{2}$ (at least 0.9712 ), but produces a $26 \% \mathrm{COV}$ when the values of all series are considered.

276 Lastly, regarding the quantification of $t^{*}$ and $n$, the obtained results were somewhat more satisfactory. Apart from the high variability of the retardation time in Series I (see Table 4 and Figure $11 \mathrm{~d}$ ), the average value of $t^{*}$ was relatively constant within each series, presenting a $1 \%$ $C O V$ in Series II and III (Figure 11d). Note that if both $E_{K}$ and $t^{*}$ are in fact constant, $\eta_{K}$ can also be assumed as constant. Regarding the values of $n$, the stability of the results is notorious since the $\mathrm{COV}$ is never higher than $6 \%$ within a series, as reported in Figure 11e, and it is still $6 \%$ when all the specimens are taken into account (see Table 6).

283 Despite the relatively low number of tests performed, it was noted that some of the parameters 284 have a tendency to decrease with the age of the unmixed components. Taking a closer look at 285 Kelvin's coefficients, $E_{K}$ and $\eta_{K}$, it was observed that from the first to last series, those 286 parameters are evaluated almost as half of the original value, suggesting that the material may 287 experience an aging effect even before it is mixed. 


\subsection{Creep Curves}

289 One of the main objectives of creep tests is the definition of the creep curves, especially the creep modulus curves. For the specific case of the epoxy adhesive tested, since all the parameters are approximately constant, it is worth to mention that this proves that this material exhibits linear viscoelastic/viscoplastic tensile behaviour. Therefore, a unique creep modulus curve, $E_{\text {creep }}(t)$, can be used to describe the behaviour of the adhesive over time, regardless the applied stress level, which is simulated by the following equation:

$$
E_{\text {creep }}(t)=\frac{\sigma}{\varepsilon_{\text {creep }}(t)}=\frac{1}{\frac{1}{E_{M}}+\frac{t}{\eta_{M}}+\frac{1}{E_{K}}\left(1-\exp \left(\left(-\frac{E_{K}}{\eta_{K}} t\right)^{1-n}\right)\right)}
$$

Figure 12 depicts the creep modulus curves obtained for each series, using the parameters reported in Table 6 . The creep modulus curves are, as expected, localized within the range of strains defined by the experimental results (see Figures 12a to 12c). In Figure 12d, all the obtained curves are overlaid in order to demonstrate that the adhesive of the three tested series exhibits similar shape of creep modulus curve. However, the creep modulus has a tendency to decrease with the age when the adhesive is prepared, indicating the occurrence of an ageing effect on the adhesive constituents. Finally, it is worth mentioning that after $1000 \mathrm{~h}$ of loading, the creep modulus of the specimens decreased to $2.71 \mathrm{GPa}, 2.37 \mathrm{GPa}$ and $2.04 \mathrm{GPa}$, for Series I, II and III, respectively. Note that these reductions correspond to a decrease to $29 \%$, $27 \%$ and $23 \%$ of the material's initial stiffness (taken as $E_{M}$ ). Unfortunately, none of the analysed papers either reported the full 1000 hours period or an adhesive of similar stiffness in order to evaluate the significance of the obtained values.

\section{Conclusions}

This paper describes an experimental program carried out aiming to characterize the tensile creep behaviour of an epoxy-based structural adhesive commonly used in NSM-CFRP strengthening applications. For that purpose, three series of tensile creep tests, composed of three adhesive samples per series, were executed. By taking the obtained results, the modified Burgers model was adjusted to the obtained experimental creep strain curves.

The obtained results showed that up to sustained stress levels of $60 \%$ of the adhesive's tensile strength, the adhesive can be assumed as a linear viscoelastic/viscoplastic material and parameterized using the modified Burgers model equation. Both the creep strain and creep modulus curves obtained using the modified Burgers equation exhibited very good agreement with the experimental results. 
Furthermore, the obtained results provided a couple of qualitative observations. The first one is related to the level of strain experienced by the adhesive. While during material testing it was determined that the ultimate strain of the adhesive was about $3 \%$, when the tensile creep tests were performed, the adhesive endured 2 times that deformation level without rupturing. This fact demonstrates that after loaded, the adhesive is able of somehow reorganizing its internal structure to continuously withstand more and more deformation without rupturing. Another important remark is related to the observed loss of stiffness with the age of the adhesive container. The reduction of the values of the Kelvin components is notorious and, additional tests should be performed in order to confirm this tendency. Given this fact, and especially when the adhesive is intended for prestressed NSM-FRP, the time period between adhesive production and application should be carefully observed. This is a fundamental issue since the applied prestress level should remain as much as possible during the design life of the strengthening intervention (in general between 50 and 100 years). In this context, the occurrence of excessive creep can compromise the effectiveness of the prestressed NSM-CFRP technique that is being investigated under the framework of the present research project.

This experimental program represents a first effort aiming to increase the knowledge on the creep of structural epoxy-based adhesives. However, much more research needs to be carried out, especially regarding the influence of the environmental conditions on the creep response.

\section{Acknowledgments}

The research carried out is part of the project PreLami (PTDC/ECM/114945/2009). The first Author acknowledges the support provided by FCT grant, SFRH/BD/61756/2009. The authors would also like to acknowledge S\&P for providing the epoxy adhesive.

\section{References}

342 [1] Barros, J. A. O.; Dias, S. J. E. and Lima, J. L. T. (2007). "Efficacy of CFRP-based techniques for the flexural and shear strengthening of concrete beams", Cement and Concrete Composites Journal, Elsevier, 29(3), 203-217.

[2] Barros, J. A. O.; Dalfré, G. M. (2013). "Assessment of the effectiveness of the embedded through-section technique for the shear strengthening of RC beams", Strain International Journal, Wiley, 49(1), 75-93.

[3] De Lorenzis, L.; Teng, J. G. (2007). "Near-surface mounted FRP reinforcement: An emerging technique for strengthening structures." Composites: Part B, Elsevier, 38(2), 119-143. 
[4] Motavalli, M.; Czaderski ,C. Pfyl-Lang, K. (2011). "Prestressed CFRP for Strengthening 


\section{LiST OF FigURES}

386 Figure 1 - Representation of a NSM-FRP application on a RC beam.

387 Figure 2 - Strain evolution with time in Burgers Model.

388 Figure 3 - Tensile tests: (a) test setup and (b) stress versus strain curves.

389 Figure 4 - Mechanical creep table.

390 Figure 5 - Tensile creep tests: (a) Specimens installation and (b) Specimens under sustained load.

391 Figure 6 - Control tensile tests: (a) Series I, (b) Series II and (c) Series III.

392 Figure 7 - Failure surface of the tensile specimens: (a) Series I, (b) Series II and (c) Series III.

393 Figure 8 - Strains versus time: (a) Series I, (b) Series II and (c) Series III.

394 Figure 9 - Burgers model strain versus experimental strain: (a) Series I, (b) Series II and (c) Series III.

395 Figure 10 - Modified Burgers model strain versus experimental strain: (a) Series I, (b) Series II and (c) Series III.

396 Figure 11 - Modified Burgers model parameters: (a) $E_{M}$, (b) $\eta_{M}$, (c) $E_{K}$, (d) $t^{*}$ and (e) $n$.

397 Figure 12 - Creep modulus curves: (a) Series I, (b) Series II, (c) Series III and (d) All analytical creep modulus 398 curves.

399 


\section{FIGURES}

399

400

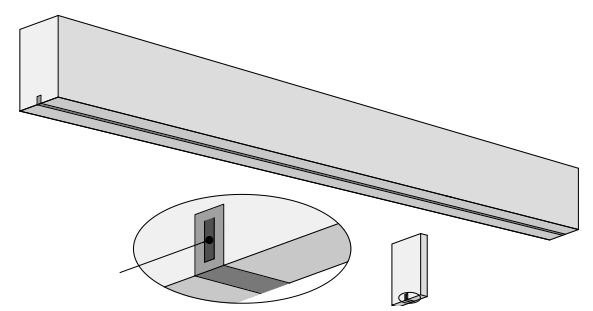

401

Figure 1 - Representation of a NSM-FRP application on a RC beam. 


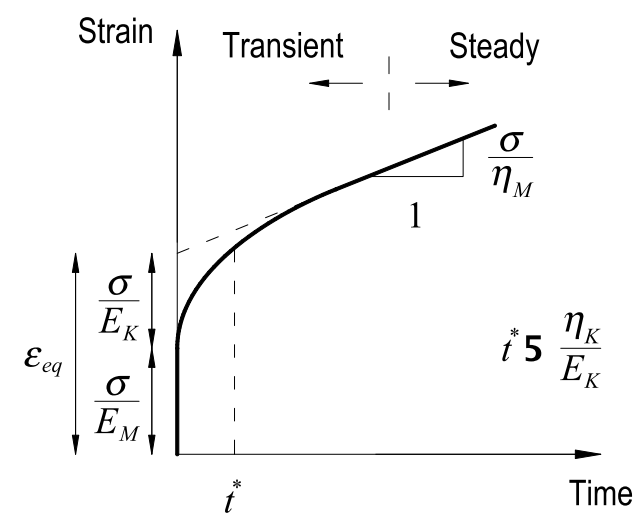

404

Figure 2 - Strain evolution with time in Burgers Model. 


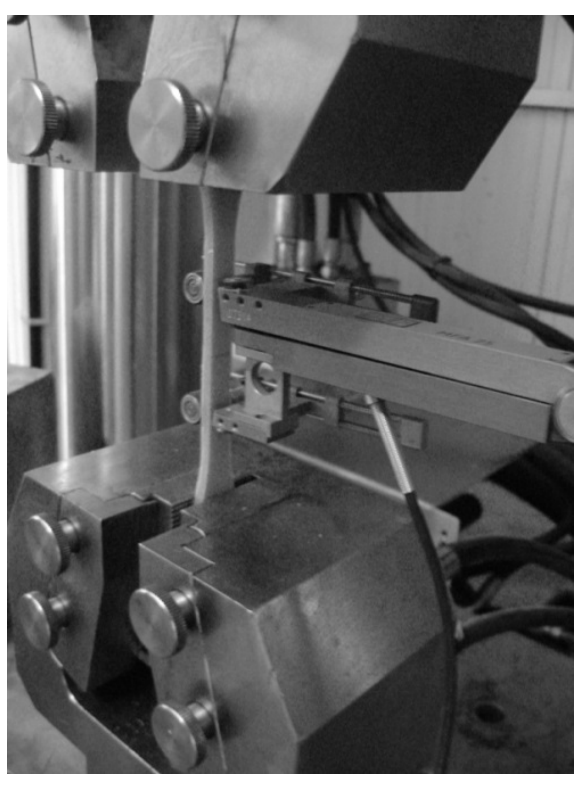

(a)

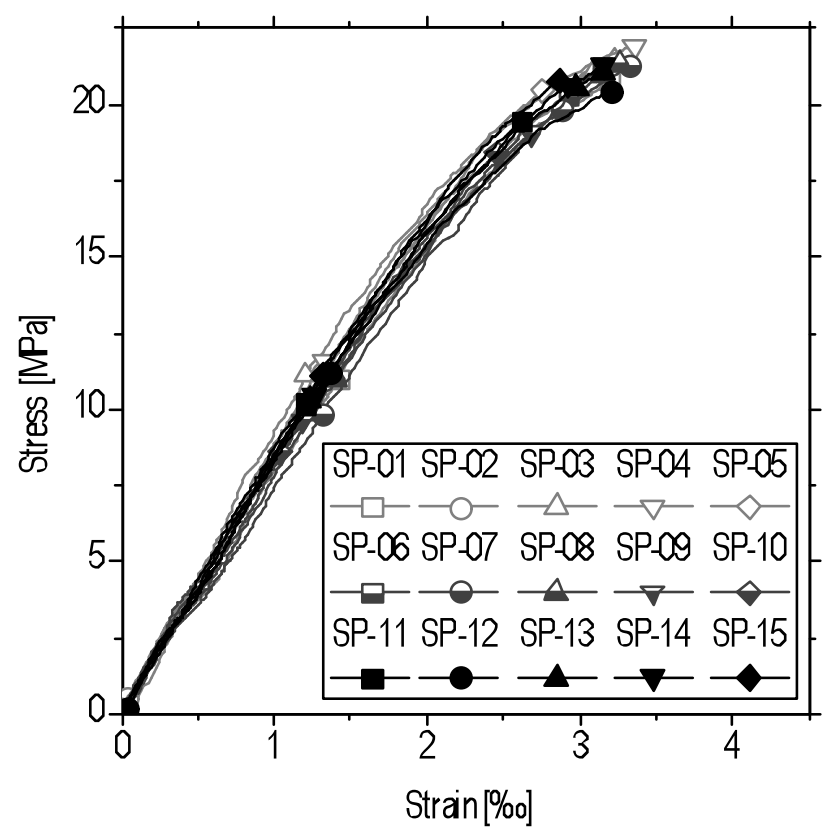

(b)

Figure 3 - Tensile tests: (a) test setup and (b) stress versus strain curves. 


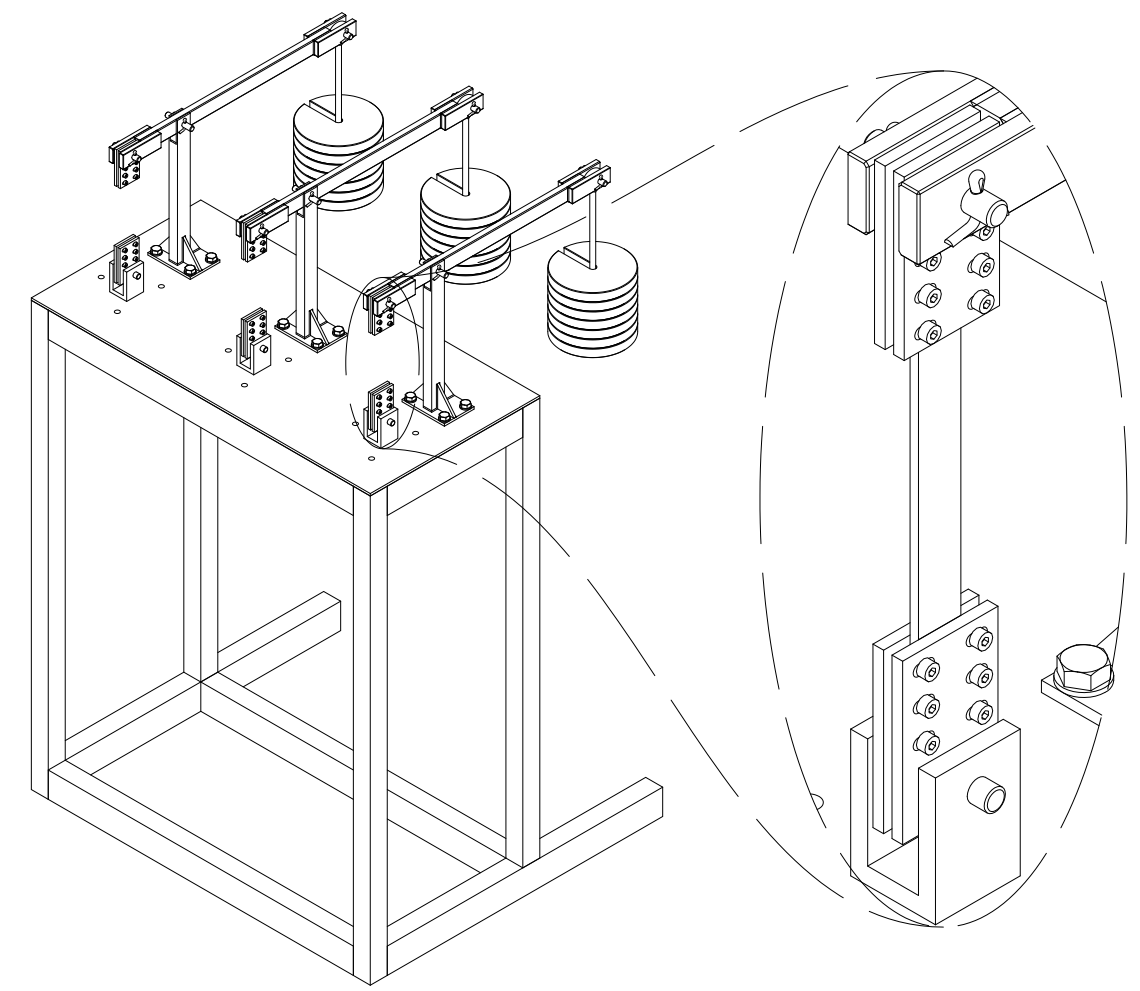

Figure 4 - Mechanical creep table. 
410

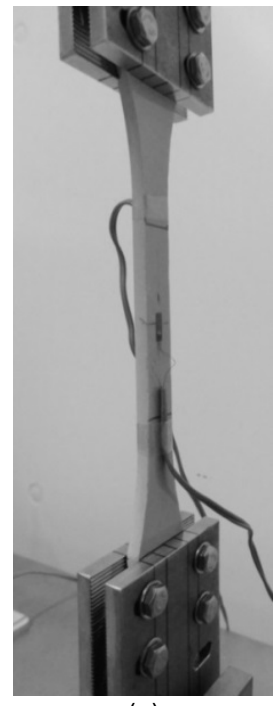

(a)

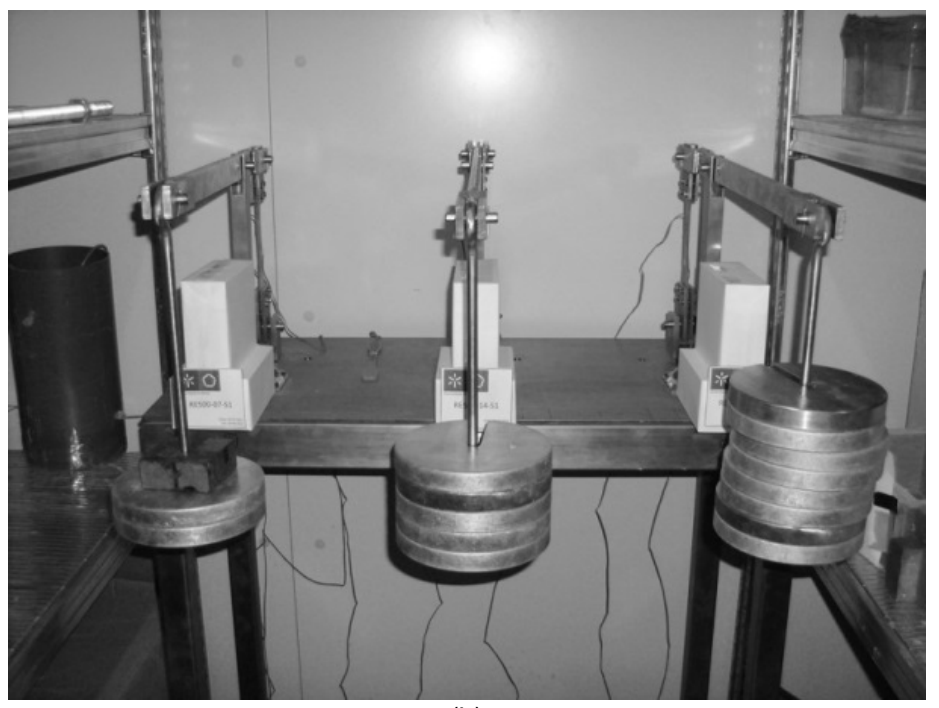

(b)

Figure 5 - Tensile creep tests: (a) Specimens installation and (b) Specimens under sustained load. 
412

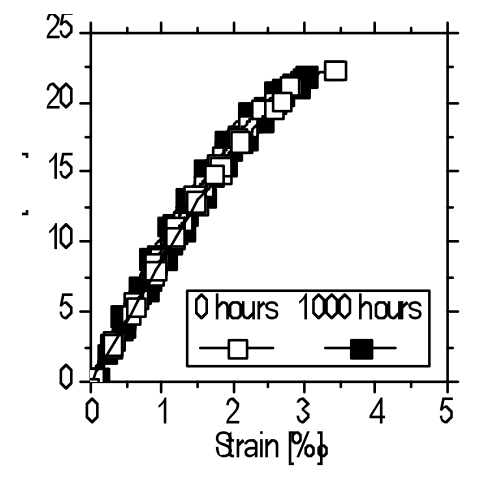

(a)

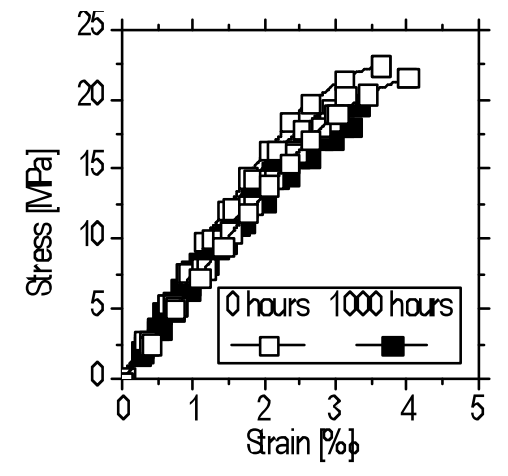

(b)

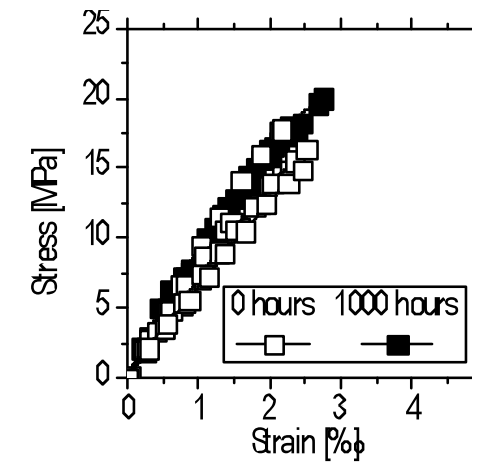

(c)

Figure 6 - Control tensile tests: (a) Series I, (b) Series II and (c) Series III. 

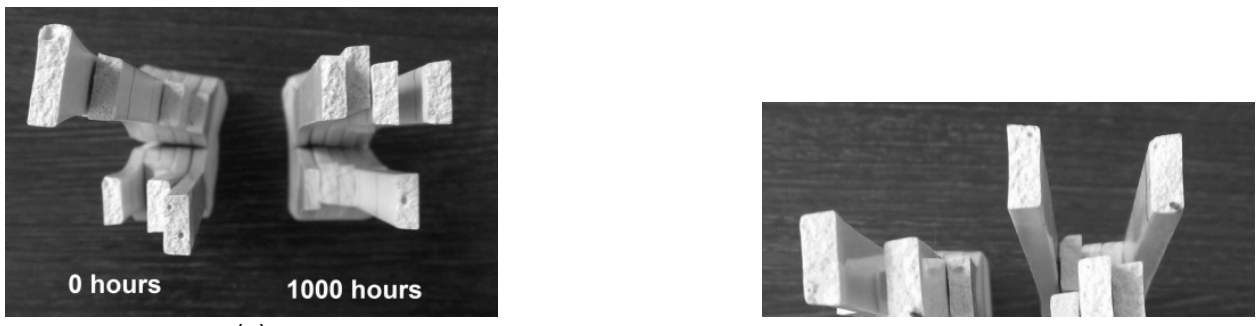

(a)

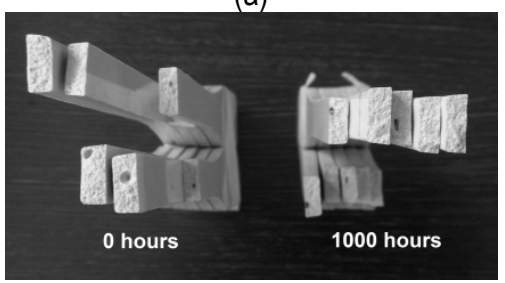

(b)

(c)

Figure 7 - Failure surface of the tensile specimens: (a) Series I, (b) Series II and (c) Series III. 
416

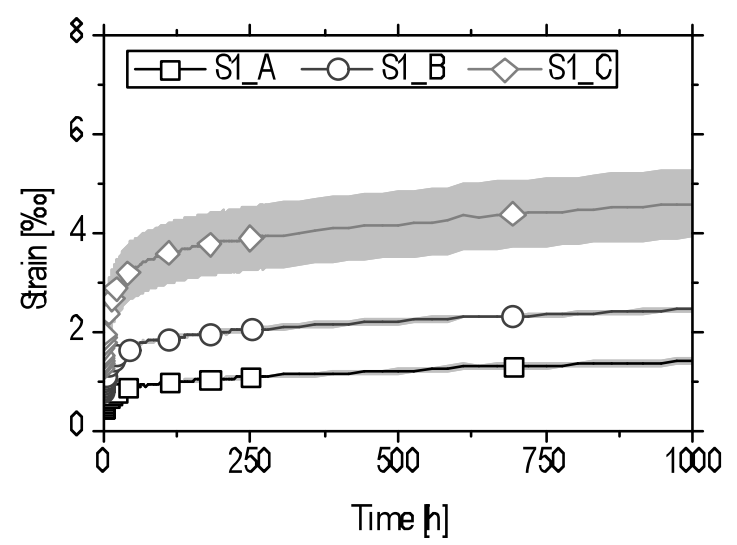

(a)

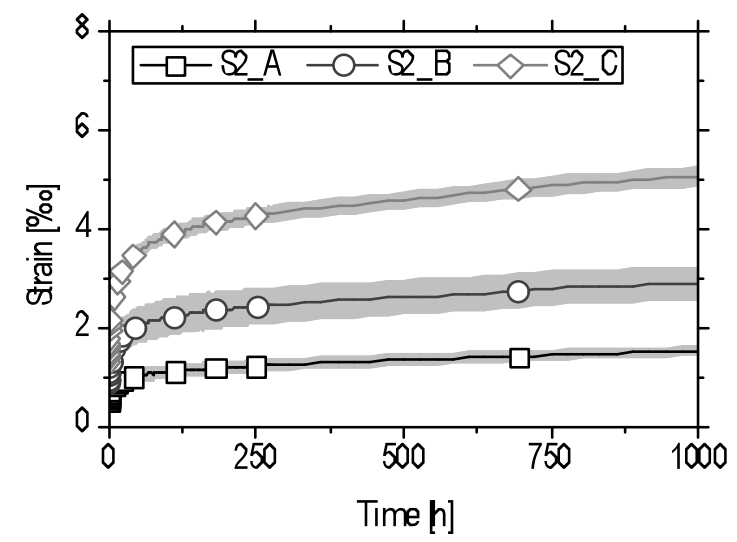

(b)

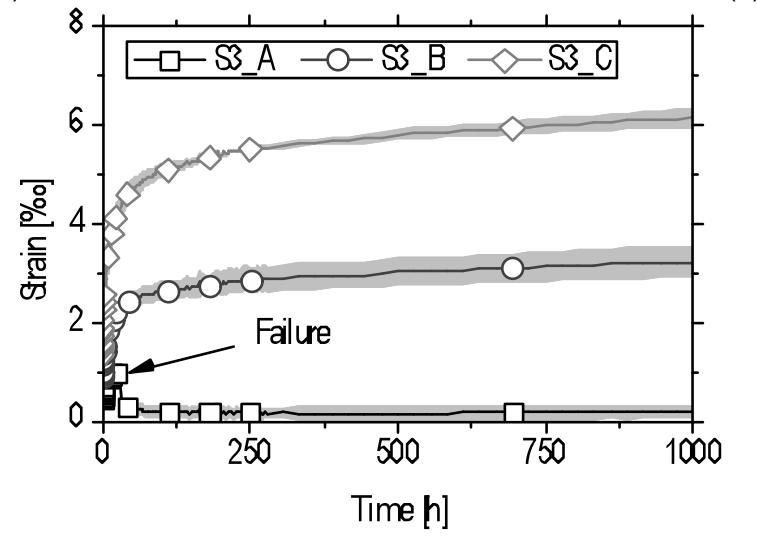

(c)

Figure 8 - Strains versus time: (a) Series I, (b) Series II and (c) Series III. 
418

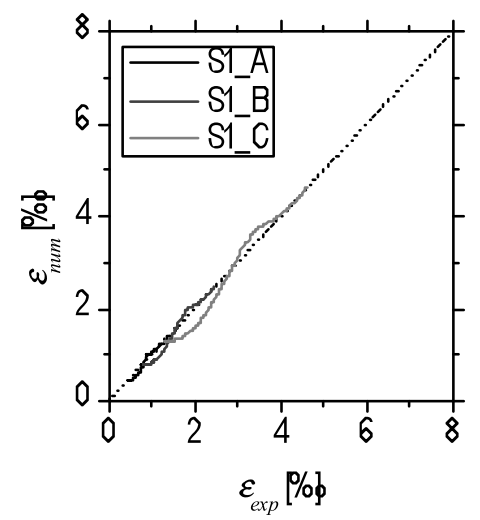

(a)

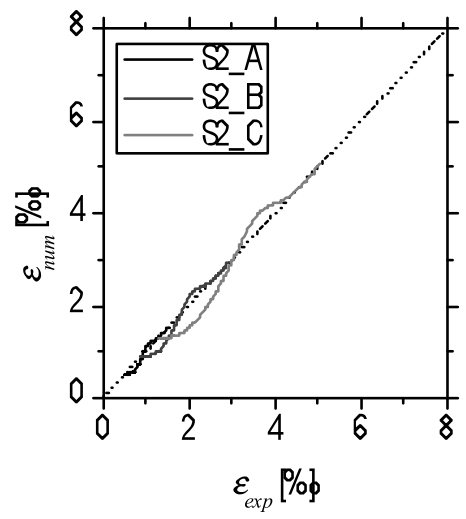

(b)

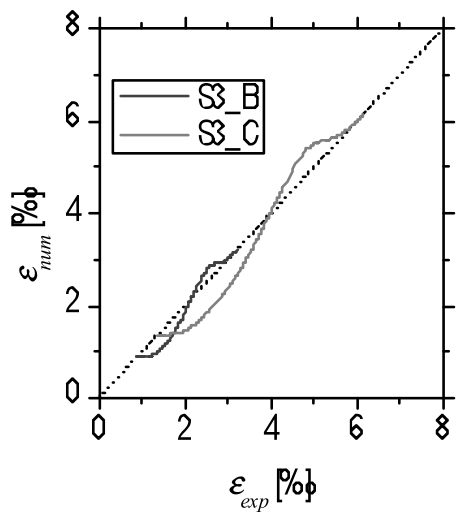

(c)

Figure 9 - Burgers model strain versus experimental strain: (a) Series I, (b) Series II and (c) Series III. 
420

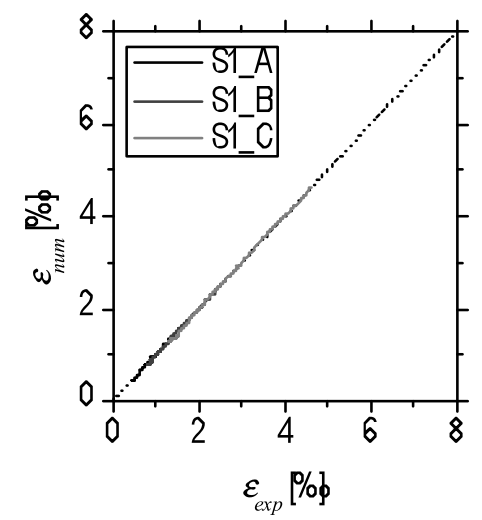

(a)

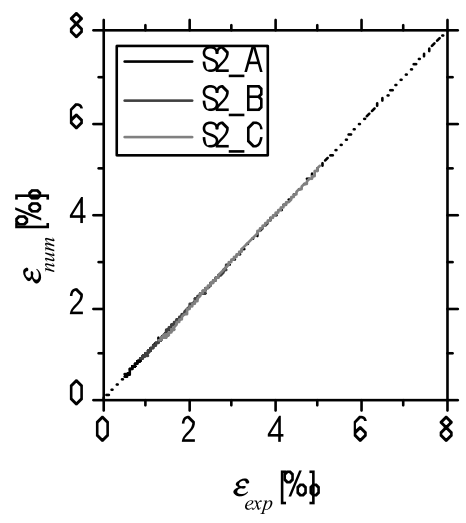

(b)

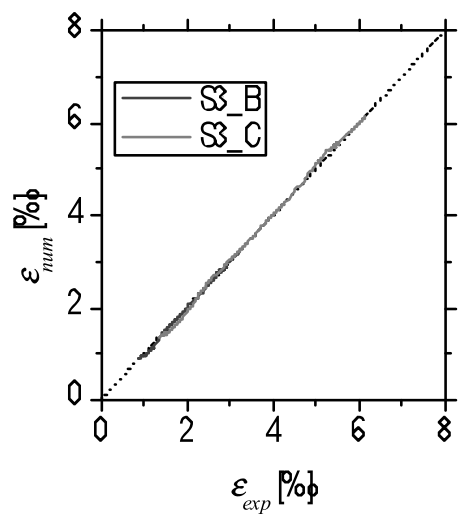

(c)

421 Figure 10 - Modified Burgers model strain versus experimental strain: (a) Series I, (b) Series II and (c) Series III. 


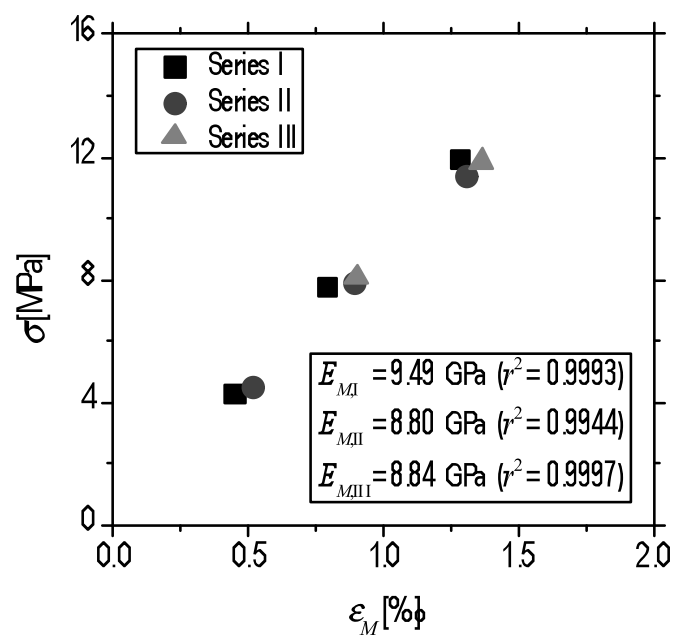

(a)

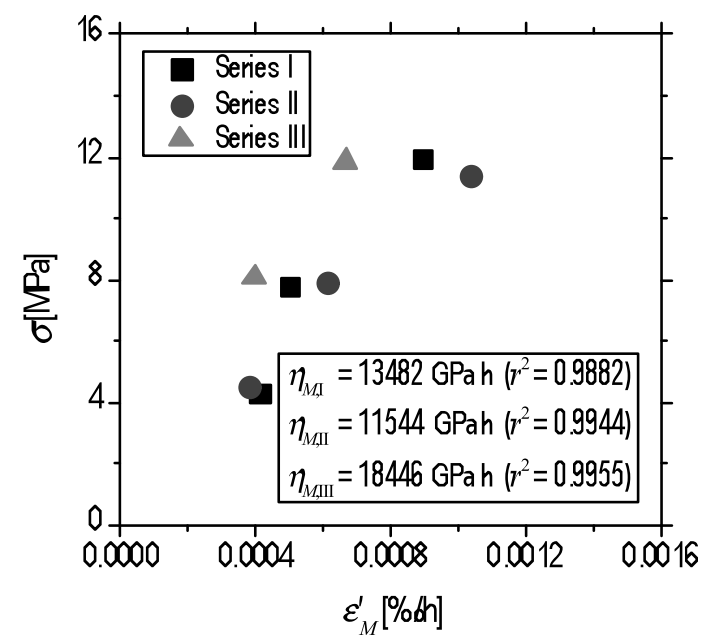

(b)

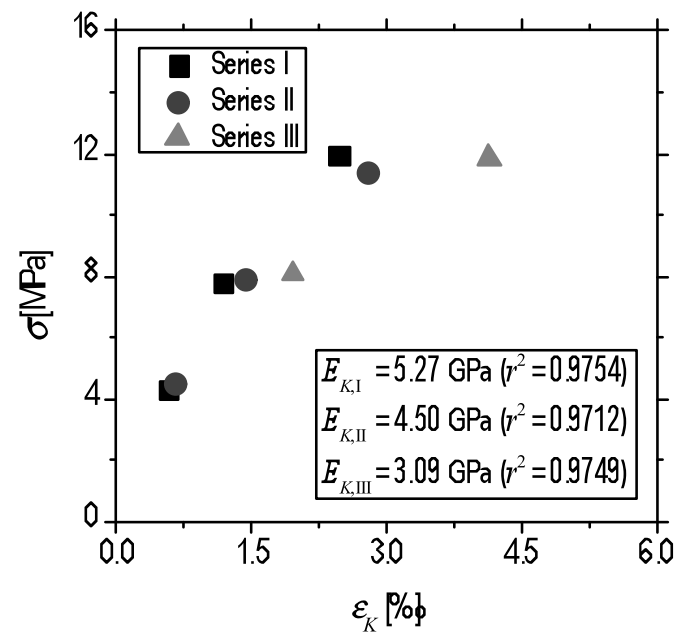

(c)

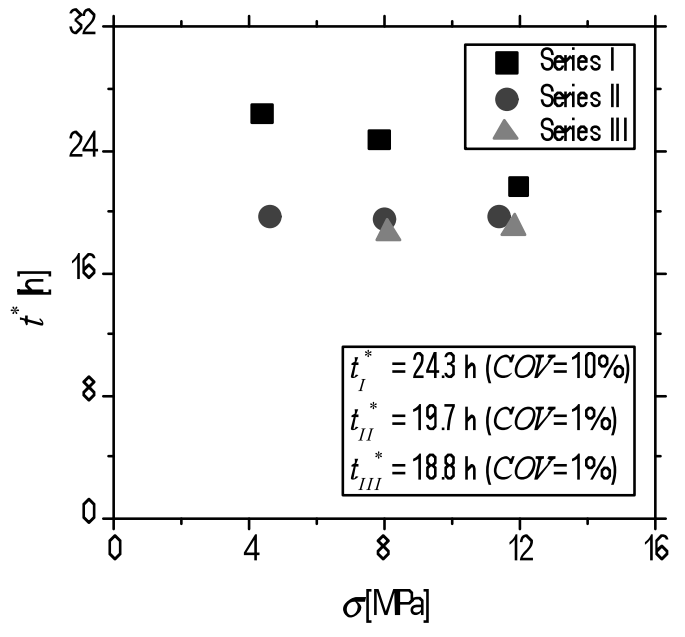

(d)

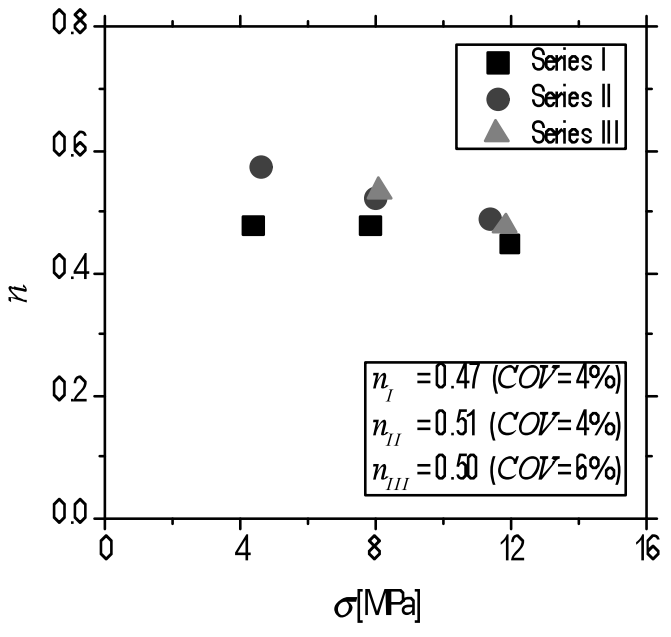

(e) 


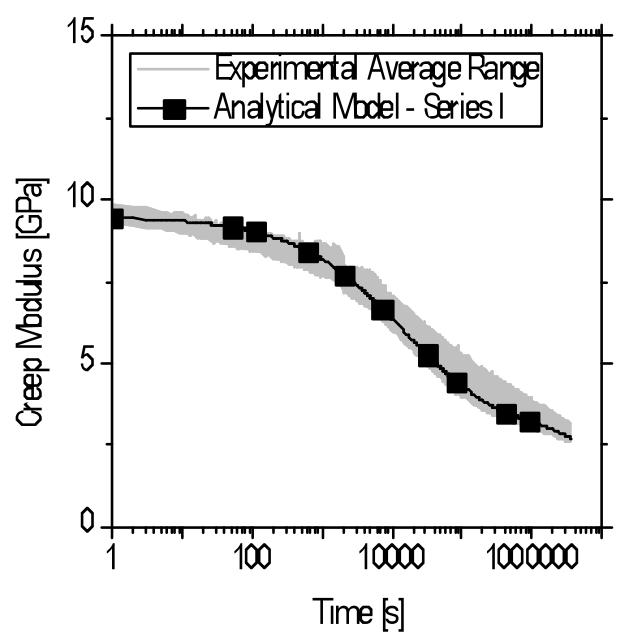

(a)

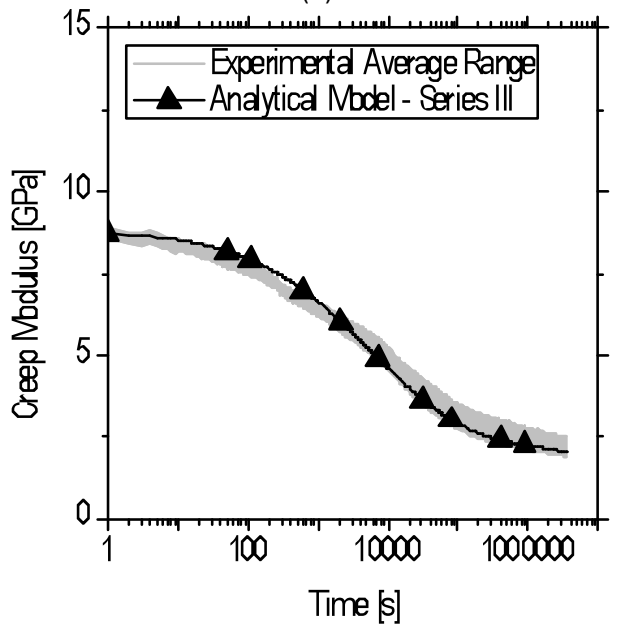

(c)

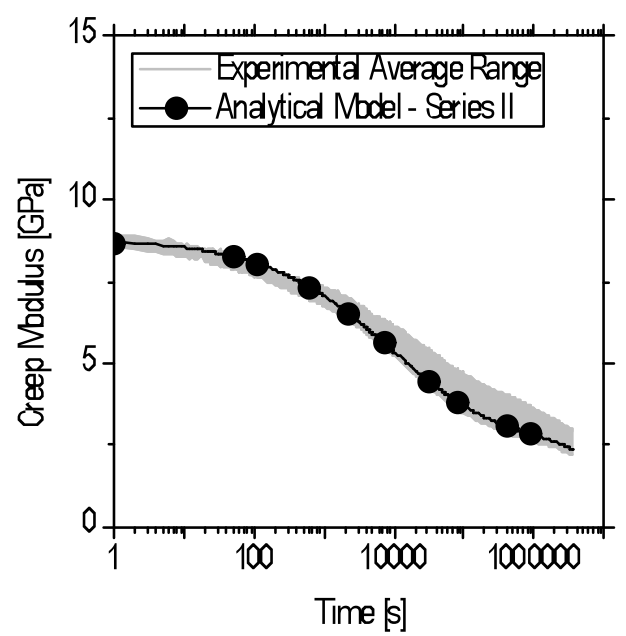

(b)

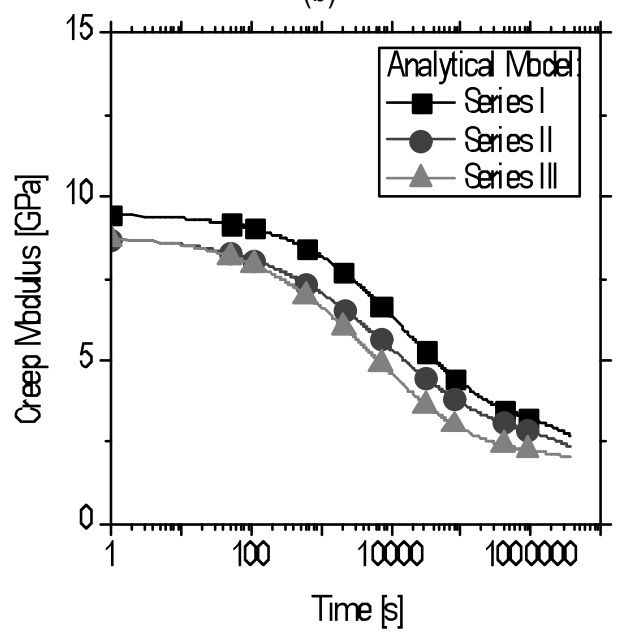

(d)

Figure 12 - Creep modulus curves: (a) Series I, (b) Series II, (c) Series III and

(d) All analytical creep modulus curves. 


\section{LIST OF TABLES}

429 Table 1 - Instantaneous properties of the epoxy adhesives.

430 Table 2 - Instantaneous properties of the creep specimens at time of loading and after $1000 \mathrm{~h}$.

431 Table 3 - Geometric properties of the specimens.

432 Table 4 - Experimental creep curve parameters.

433 Table 5 - Modified Burgers equation parameters.

434 Table 6 - Average modified Burgers equation parameters of all series tested.

435 


\section{TABLES}

435

436

Table 1 - Instantaneous properties of the epoxy adhesives.

\begin{tabular}{cccccc}
\hline Specimen & $\begin{array}{c}\text { Curing time } \\
\text { [days] }\end{array}$ & $\begin{array}{c}E_{a} \\
{[\mathrm{GPa}]}\end{array}$ & $r^{2}$ & $\begin{array}{c}f_{a} \\
{[\mathrm{MPa}]}\end{array}$ & $\begin{array}{c}\varepsilon_{a} \\
{[\%]}\end{array}$ \\
\hline SP-01 & & 7.53 & 0.9961 & 20.9 & 3.20 \\
SP-02 & & 7.41 & 0.9916 & 20.8 & 3.07 \\
SP-03 & 2 & 7.47 & 0.9901 & 21.4 & 3.22 \\
SP-04 & & 7.67 & 0.9949 & 21.9 & 3.36 \\
SP-05 & & 7.86 & 0.9983 & 20.5 & 2.76 \\
Average & & $7.59(0.18)\{2 \%\}$ & - & $21.1(0.6)\{3 \%\}$ & $3.12(0.23)\{7 \%\}$ \\
\hline SP-06 & & 7.37 & 0.9958 & 21.2 & 3.14 \\
SP-07 & & 7.32 & 0.9977 & 21.3 & 3.32 \\
SP-08 & 3 & 7.39 & 0.9961 & 21.3 & 3.26 \\
SP-09 & & 7.19 & 0.9934 & 19.0 & 2.69 \\
SP-10 & & 6.99 & 0.9978 & 18.4 & 2.46 \\
Average & & $7.25(0.17)\{2 \%\}$ & - & $20.2(1.4)\{7 \%\}$ & $2.97(0.38)\{13 \%\}$ \\
\hline SP-11 & & 7.42 & 0.9952 & 19.5 & 2.62 \\
SP-12 & & 7.00 & 0.9942 & 20.5 & 3.20 \\
SP-13 & 7 & 7.47 & 0.9948 & 21.1 & 3.15 \\
SP-14 & & 7.40 & 0.9959 & 21.3 & 3.15 \\
SP-15 & & 7.83 & 0.9955 & 20.8 & 2.87 \\
Average & & $7.42(0.29)\{4 \%\}$ & - & $20.6(0.7)\{3 \%\}$ & $3.00(0.25)\{8 \%\}$ \\
\hline
\end{tabular}

$437 \quad r^{2}$ is the coefficient of determination of the linear regression of the stress versus strain curve.

438 Average deviation) $\quad$ (Soefficient $\quad$ of $\quad$ variation\} 
Table 2 - Instantaneous properties of the creep specimens at time of loading and after $1000 \mathrm{~h}$.

\begin{tabular}{|c|c|c|c|c|c|c|c|}
\hline \multirow[b]{2}{*}{ Series } & \multirow{2}{*}{$\begin{array}{l}\text { Age of the } \\
\text { Adhesive } \\
\text { Container } \S\end{array}$} & \multicolumn{2}{|c|}{$t=0 \mathrm{~h}$} & \multicolumn{2}{|c|}{$t=1000 \mathrm{~h}$} & \multirow[b]{2}{*}{$\begin{array}{r}\Delta E_{a} \\
{[\%]}\end{array}$} & \multirow[b]{2}{*}{$\begin{array}{l}\Delta f_{a} \\
{[\%]}\end{array}$} \\
\hline & & $\begin{array}{c}E_{a} \\
{[\mathrm{GPa}]}\end{array}$ & $\begin{array}{c}f_{a} \\
{[\mathrm{MPa}]}\end{array}$ & $\begin{array}{c}E_{a} \\
{[\mathrm{GPa}]}\end{array}$ & $\begin{array}{c}f_{a} \\
{[\mathrm{MPa}]}\end{array}$ & & \\
\hline I & $\approx 9$ days & $7.70(0.16)\{2 \%\}$ & $20.2(2.2)\{11 \%\}$ & $7.61(0.29)\{4 \%\}$ & $20.9(1.3)\{6 \%\}$ & -1.1 & 3.3 \\
\hline$\|$ & $\approx 69$ days & $6.79(0.41)\{6 \%\}$ & $20.3(1.7)\{8 \%\}$ & $6.36(0.29)\{5 \%\}$ & $17.7(1.6)\{9 \%\}$ & -6.4 & -13.2 \\
\hline III & $\approx 124$ days & $6.72(0.74)\{11 \%\}$ & $15.0(2.5)\{16 \%\}$ & $7.36(0.84)\{11 \%\}$ & $15.7(5.4)\{35 \%\}$ & 9.6 & 4.5 \\
\hline
\end{tabular}

$441 \S$ Refers to the time between the reception of the adhesive container and the mixture of components.

442 Average (Standard deviation) \{Coefficient of variation\}

$443 \Delta E_{a}=\left(E_{a, t=1000 h}-E_{a, t=0 h}\right) / E_{a, t=0 h}$;

$\Delta f_{a}=\left(f_{a, t=1000 h}-f_{a, t=0 h}\right) / f_{a, t=0 h}$ 
Table 3 - Geometric properties of the specimens.

\begin{tabular}{|c|c|c|c|c|c|c|}
\hline Series & Specimen & $\begin{array}{c}W \\
{[\mathrm{~kg}]}\end{array}$ & $\begin{array}{c}A \\
{\left[\mathrm{~mm}^{2}\right]}\end{array}$ & $\begin{array}{c}\sigma \\
{[\mathrm{MPa}]}\end{array}$ & $\begin{array}{c}\% f_{\max , 0 h} \\
{[\%]}\end{array}$ & $\begin{array}{c}\% f_{1000 h} \\
{[\%]}\end{array}$ \\
\hline \multirow{3}{*}{ I } & S1_A & 6 & 43.486 & 4.32 & 21 & 21 \\
\hline & S1_B & 11 & 43.278 & 7.81 & 39 & 37 \\
\hline & S1_C & 17 & 43.067 & 11.94 & 59 & 57 \\
\hline \multirow{3}{*}{ II } & S2_A & 6 & 41.272 & 4.55 & 22 & 26 \\
\hline & S2_B & 11 & 42.494 & 7.95 & 39 & 45 \\
\hline & S2_C & 17 & 45.296 & 11.35 & 56 & 64 \\
\hline \multirow{3}{*}{ III } & S3_A & 6 & 42.003 & 4.47 & 30 & 28 \\
\hline & S3_B & 11 & 41.763 & 8.09 & 54 & 51 \\
\hline & S3_C & 17 & 43.487 & 11.82 & 79 & 75 \\
\hline
\end{tabular}

446 The creep apparatus used magnifies the applied dead weight in 3 times meaning that $\varphi=3$.

$447 \% f_{\max , 0 h}=\sigma / f_{a, 0 h}$

and

$\% f_{0 h}=\sigma / f_{a, 1000 h}$. 

Table 4 - Experimental creep curve parameters.

\begin{tabular}{|c|c|c|c|c|c|c|c|c|c|c|c|c|}
\hline Series & Specimen & $\begin{array}{l}\varepsilon_{M} \\
{[\% 0]}\end{array}$ & $\begin{array}{c}\varepsilon_{M}^{\prime} \\
{[\% / h]}\end{array}$ & & $\begin{array}{l}\varepsilon_{e q} \\
{[\% 0]}\end{array}$ & $\begin{array}{l}\varepsilon_{e q} \\
{[\% 0]}\end{array}$ & $\begin{array}{l}t^{*} \\
{[\mathrm{~h}]}\end{array}$ & $\begin{array}{c}E_{M} \\
{[\mathrm{GPa}]}\end{array}$ & $\begin{array}{c}\eta_{M} \\
{[\mathrm{GPa} \cdot \mathrm{h}]}\end{array}$ & $\begin{array}{c}E_{K} \\
{[\mathrm{GPa}]}\end{array}$ & $\begin{array}{c}\eta_{K} \\
{[\mathrm{GPa} \cdot \mathrm{h}]}\end{array}$ & $\begin{array}{c}M A P E \\
{[\%]}\end{array}$ \\
\hline \multirow{3}{*}{ I } & S1_A & 0.445 & \multicolumn{2}{|c|}{$4.099 \mathrm{e}-04$} & 1.011 & 0.566 & 26.5 & 9.71 & 10545 & 7.64 & 202 & 8 \\
\hline & S1_B & 0.789 & \multicolumn{2}{|c|}{$4.993 \mathrm{e}-04$} & 1.969 & 1.180 & 24.8 & 9.90 & 15640 & 6.62 & 164 & 9 \\
\hline & S1_C & 1.282 & \multicolumn{2}{|c|}{$8.891 \mathrm{e}-04$} & 3.750 & 2.468 & 21.8 & 9.31 & 13425 & 4.84 & 105 & 10 \\
\hline \multirow{3}{*}{ II } & S2_A & 0.511 & \multicolumn{2}{|c|}{$3.770 \mathrm{e}-04$} & 1.168 & 0.657 & 19.6 & 8.91 & 12079 & 6.93 & 137 & 10 \\
\hline & S2_B & 0.888 & \multicolumn{2}{|c|}{$6.117 \mathrm{e}-04$} & 2.321 & 1.433 & 19.8 & 8.96 & 13001 & 5.55 & 109 & 10 \\
\hline & S2_C & 1.304 & \multicolumn{2}{|c|}{$1.035 \mathrm{e}-03$} & 4.080 & 2.776 & 19.7 & 8.71 & 10964 & 4.09 & 81 & 12 \\
\hline \multirow{3}{*}{ I } & S3_A & 0.466 & \multicolumn{2}{|l|}{-} & - & - & - & 9.61 & - & - & - & - \\
\hline & S3_B & 0.898 & \multicolumn{2}{|c|}{$3.938 \mathrm{e}-04$} & 2.850 & 1.952 & 19.0 & 9.02 & 20547 & 4.14 & 77 & 13 \\
\hline & S3_C & 1.363 & \multicolumn{2}{|c|}{$6.673 e-04$} & 5.499 & 4.136 & 18.8 & 8.67 & 17714 & 2.86 & 54 & 14 \\
\hline
\end{tabular}

451 sampling point $i$, respectively, and $N$ is the number of sampling points $(N=487)$. 
452

453

Table 5 - Modified Burgers equation parameters.

\begin{tabular}{|c|c|c|c|c|}
\hline Series & Specimen & $n$ & $r^{2}$ & $\begin{array}{c}M A P E \\
{[\%]}\end{array}$ \\
\hline \multirow{3}{*}{1} & S1_A & 0.48 & 0.9984 & 2 \\
\hline & S1_B & 0.48 & 0.9995 & 2 \\
\hline & S1_C & 0.45 & 0.9996 & 2 \\
\hline \multirow{3}{*}{$\|$} & S2_A & 0.57 & 0.9990 & 1 \\
\hline & S2_B & 0.52 & 0.9995 & 2 \\
\hline & S2_C & 0.49 & 0.9995 & 2 \\
\hline \multirow{3}{*}{ III } & S3_A & - & - & - \\
\hline & S3_B & 0.53 & 0.9986 & 2 \\
\hline & S3_C & 0.48 & 0.9992 & 3 \\
\hline
\end{tabular}

454

Page 31 of 32 
Table 6 - Average modified Burgers equation parameters of all series tested.

\begin{tabular}{ccccccc}
\hline Parameter & $\begin{array}{c}E_{M} \\
{[\mathrm{GPa}]}\end{array}$ & $\begin{array}{c}\eta_{M} \\
{[\mathrm{GPa} \cdot \mathrm{h}]}\end{array}$ & $\begin{array}{c}E_{K} \\
{[\mathrm{GPa}]}\end{array}$ & $\begin{array}{c}t^{*} \\
{[\mathrm{~h}]}\end{array}$ & $\begin{array}{c}\eta_{K} \\
{[\mathrm{GPa} \cdot \mathrm{h}]}\end{array}$ & $n$ \\
\hline Series I & 9.49 & 13482 & 5.27 & 24.3 & 128 & 0.47 \\
Series II & 8.80 & 11544 & 4.50 & 19.7 & 88.7 & 0.53 \\
Series III & 8.84 & 18446 & 3.09 & 18.8 & 58.1 & 0.50 \\
\hline \multirow{2}{*}{ Average } & $9.04(0.39)$ & $14491(3560)$ & $4.29(1.10)$ & $20.9(3.0)$ & $91.7(35.2)$ & $0.50(0.03)$ \\
& $\{4 \%\}$ & $\{25 \%\}$ & $\{26 \%\}$ & $\{14 \%\}$ & $\{38 \%\}$ & $\{6 \%\}$ \\
\hline
\end{tabular}

Average (Standard Deviation) \{Coefficient of Variation\} 